\title{
Outcomes and complications of self-expanding metal stent placement for malignant colonic obstruction in a single-center study
}

\author{
Rafał Stankiewicz, Sławomir Kozieł, Jan Pertkiewicz, Krzysztof Zieniewicz \\ Department of General Transplant and Liver Surgery, Medical University of Warsaw, Warsaw, Poland
}

Videosurgery Miniinv 2018; 13 (1): 53-56

DOI: https://doi.org/10.5114/wiitm.2017.70194

\begin{abstract}
Introduction: Approximately 20\% of cases of colorectal cancer are accompanied by acute colonic obstruction. While emergency colonic surgery is associated with high mortality and morbidity rates, placement of a self-expanding metal stent (SEMS) has been suggested as an alternative method. The SEMS placement can serve as either a definitive treatment in palliative cases or a bridge to surgery.

Aim: To summarize the experience of our center in the treatment of malignant colonic obstruction using SEMS placement.

Material and methods: A retrospective review was conducted of all patients who underwent a SEMS placement for colorectal stricture in the study period. The procedures were performed under fluoroscopic guidance with colonoscopic assistance, and uncovered stents were used in all patients.

Results: The study population consisted of 28 patients treated with SEMS placement due to malignant colonic obstruction. The majority of procedures were performed with palliative intent. The overall technical success rate was $96.5 \%$, and clinical success was achieved in all of the successfully placed SEMSs. One fatal complication due to colonic perforation occurred. In the bridge-to-surgery group, all patients experienced tumor resection with no stoma creation.

Conclusions: The SEMS placement is an optimal treatment in the vast majority of acute colonic obstruction cases. Due to the possibility of potentially fatal complications, SEMS procedures should be performed by proficient endoscopists.
\end{abstract}

Key words: complications, self-expandable metal stent, colonic obstruction, colon perforation, self-expanding metal stent.

\section{Introduction}

Colorectal cancer is one of the most common malignant diseases, and it is accompanied by acute colonic obstruction in approximately $20 \%$ of cases $[1,2]$. Emergency colorectal surgery is associated with high mortality and morbidity rates, and the 30-day postoperative mortality rate for emergency surgery has been recently reported to be $14.9 \%$ compared with $5.8 \%$ for elective surgery [3-5]. Co- lonic self-expanding metal stent (SEMS) placement has been suggested as an alternative to surgery for malignant large bowel obstruction. Dohmoto first described the use of colonic stents in patients with non-resectable or metastatic rectal cancer in 1991 [6]. In 1994, Tejero et al. published their experience of SEMS in patients with colonic obstruction as a bridge to definitive surgery [7]. This procedure seems to offer good palliation and, where possible, serves as a safe and effective "bridge to surgery"

\section{Address for correspondence}

Rafał Stankiewicz MD, Department of General Transplant and Liver Surgery, Medical University of Warsaw, 1a Banacha St,

02-097 Warsaw, Poland, phone: +48 2259925 45, e-mail: rstankiewicz0@gmail.com 
that facilitates single-stage surgery [8]. Further advantages of SEMS include the reduction of stomas and low mortality and morbidity rates [9]. However, SEMS is associated with important complications such as bowel perforation and stent migration [10].

\section{Aim}

The aim of this study was to summarize the experience of our center in the treatment of malignant colonic obstructions using SEMS placement.

\section{Material and methods}

A retrospective review of all patients who underwent SEMS placement for colorectal stricture between October 2010 and October 2016 was conducted. The inclusion criteria for the procedure consisted of: 1) symptoms and signs of colonic obstruction, and 2) documented malignancy affecting the colon. Patients with intestinal perforation and serious hemorrhage of the colon did not qualify for SEMS placement. All SEMS procedures were performed by two surgeons (SK, JP) who were proficient in therapeutic endoscopy. The procedures were performed under

Table I. Overall characteristics

\begin{tabular}{|lc|}
\hline Parameter & $N(\%)$ \\
\hline Mender: & $18(64)$ \\
\hline Female & $10(36)$ \\
\hline \begin{tabular}{l} 
Cause of obstruction: \\
\hline Colon primary tumor
\end{tabular} & $24(86)$ \\
\hline Extrinsic compression & $1(3)$ \\
\hline $\begin{array}{l}\text { Tumor recurrence } \\
\text { Intent of intervention: }\end{array}$ & $23(82)$ \\
\hline \begin{tabular}{l} 
Palliative \\
\hline Bridge to surgery
\end{tabular} & $1(18)$ \\
\hline $\begin{array}{l}\text { Rectosigmoid } \\
\text { Splenic flexure }\end{array}$ & $3(11)$ \\
\hline
\end{tabular}

fluoroscopic guidance with colonoscopic assistance, and uncovered stents with a diameter of $25 \mathrm{~mm}$ were used in all patients. The choice of which SEMS to use (with respect to length) was made according to the characteristics of the stricture. Balloon dilatation was not routinely performed. Technical success was defined as the successful deployment of the stent, and clinical success was defined as the relief of obstructive symptoms or signs within $48 \mathrm{~h}$ of stent deployment. All patients were observed in the recovery unit for $1-3 \mathrm{~h}$ and then transferred to the ward. Signed written informed consent was obtained from all patients before the procedure. Stents were considered a bridge therapy to surgery not only if the stent was placed initially for this purpose, but also if the patient ended up undergoing surgery. This is because 2 patients did not give consent for surgical treatment and were therefore considered as receiving palliative treatment. For this study no separate Bioethics Committee approval was obtained due to its retrospective character.

\section{Results}

A total of 31 SEMS procedures were performed in 28 patients during the study. The mean age of the group was 70 years (range: 38-94 years). Other group characteristics are presented in Table I. The majority of the procedures were performed with palliative intent (23/28), and the most common cause of obstruction was a primary colon tumor (24/28) located in the sigmoid (15/28). The extrinsic compressions were due to genitourinary and gastric cancers. Median time of the procedure was 30 min (range: 22-46 min). Median length of the stricture was $4 \mathrm{~cm}$ (range: $2-5 \mathrm{~cm}$ ), similar in both groups. The overall technical success rate was $96.5 \%$ (27/28). Among those with successfully placed SEMSs, clinical success was achieved in all cases. The overall complication rate was $19.4 \%(6 / 31)$.

\section{Palliative group}

The palliative group consisted of 23 patients (14 male, 9 female). The mean age was 68 years (range: 38-94). The most common reason for palliative treatment was unresectable distant metastases in $12(52 \%)$ patients, followed by severe comorbidities in 5 (22\%), other organ cancers invading the colorectum in $3(13 \%)$, unresectable recurrent colorectal cancer in 1 (4\%), and lack of patient's consent for 
surgery in 2 (9\%). The obstruction was located in the rectum, rectosigmoid, sigmoid, and splenic flexure in $8,3,9$, and 3 patients, respectively.

The technical success rates were 95.5\% (22/23) for initial placements and 100\% (3/3) for secondary placements. Technical failure was due to the inability of the guidewire to traverse the stricture. Secondary stent placement was required in 2 patients due to stent obstruction by tumor ingrowth after 178 and 296 days, and in 1 patient due to stent migration after 155 days. Endoscopic balloon dilatation of the stricture was performed in 5 patients.

Procedure-related complications were observed in $6(26 \%)$ patients: perforation in 4 , stent migration in 1 , and bleeding in 1 . Two patients with perforation underwent an emergency Hartmann's procedure. One patient experienced perforation of the small intestine 1 day after the procedure and underwent resection of the perforated jejunum. One patient with perforation denied consent for surgery, with a fatal outcome. The patient with tumor bleeding was treated conservatively with satisfactory results. During the follow-up period, reobstruction occurred in 2 (9\%) patients, and both were treated with stent-in-stent placement. In 1 patient, late perforation occurred 6 months after the second intervention, which was treated with an emergency Hartmann's procedure.

\section{Bridge-to-surgery group}

The bridge-to-surgery group consisted of 5 patients (4 male, 1 female) with a mean age of 76 years (range: 53-91). Four patients had obstructive sigmoid cancer that was treated definitively with sigmoidectomy, and in 1 patient the tumor was located in the descending colon and was treated with left hemicolectomy. Definitive treatment was performed an average of 18 days (range: 5-42) after initial stent placement. Technical and clinical success rates of $100 \%$ each were achieved. No procedure-related complications were observed.

\section{Discussion}

Treatment of colonic obstruction by SEMS placement has over 20 years of history $[6,7]$. In recently published clinical guidelines [10] that summarize this period and determine future directions, Van Hooft et al. emphasize the role of SEMS as a method of palliation and minimize its value as a bridge to surgery.
In the present study, in the majority of cases, SEMS placement was used as a palliative treatment with technical and clinical success rates of $96.5 \%$ and $100 \%$, respectively. Saida et al. [11] reported technical and clinical success rates of $91 \%$ and $89 \%$, respectively, and Samper Wamba et al. reported a technical success rate of $92.26 \%$ and a clinical success rate of $78.45 \%$ in a sample of 478 patients [12].

In the present study, all patients in the bridge-tosurgery group underwent definitive surgery after an average of 18 days. No permanent or protective stomas were created. These results are in accordance with the meta-analysis by Takahashi et al. in which the authors concluded that SEMS placement significantly reduces the risk for stoma creation in obstructive left-sided colorectal cancer [13].

Unfortunately, some complications could not be avoided. The overall complication rate of $19.4 \%$ in our study was high in comparison to the $4 \%$ complication rate in a study by Saida et al. [11]. Moreover, the $18.5 \%$ complication rate achieved in 441 procedures in the study by Samper Wamba et al. seems to offer a better perspective on the actual level of procedure-related risk [12]. The perforation rate of $12.9 \%(4 / 31)$ in the present study slightly exceeds that reported in the European Society of Gastrointestinal Endoscopy (ESGE) guidelines [10]. While perforation of the colon can be expected after SEMS placement, the perforation of the small intestine in a location unrelated to the obstructive tumor 1 day after the procedure cannot be easily explained. The mortality rate of $3.5 \%(1 / 28)$ in this study is consistent with that in previous reports [14-16]. Notably, all adverse events occurred in the palliative group.

In 2015, Miłek et al. presented the largest cohort of patients from a Polish center [17]. In their study, 95 patients exceeding 70 years of age with colorectal cancer were treated with either palliative or bridge-to-surgery stent placement. Only interventional radiology was used with no endoscopic guidance, resulting in a $100 \%$ success rate and low morbidity.

According to the data acquired from medical companies providing metallic stents to various hospitals in Poland, this method is gaining wider acceptance in the surgical community [unpublished data]. Approximately 27 centers around Poland are using this procedure, with an average of three SEMS placements per year. These numbers are limited by two factors. The first is the lack of surgeons/endos- 
copists who are proficient in therapeutic endoscopy with the experience of at least 20 colonic stent placement procedures. The second is the fact that this procedure is not cost-effective in Poland, as the costs of the procedure and the stent itself are not refundable by the Ministry of Health.

The main limitation of this study is its retrospective design with a relatively small sample size. Despite this limitation, we truly believe that our study provides valuable data on the treatment of colonic obstruction with SEMS placement in a single center in Poland.

\section{Conclusions}

The SEMS placement is an optimal treatment in the majority of acute colonic obstruction cases. To avoid the risk of potentially fatal complications, SEMS procedures should be performed by proficient endoscopists. The availability of this method should be supported by the authorities in light of its undeniable advantages, especially for palliative patients.

\section{Conflict of interest}

The authors declare no conflict of interest.

\section{References}

1. Ohman U. Colorectal carcinoma in patients with ulcerative colitis. Am J Surg 1982; 144: 344-9.

2. Deans GT, Krukowski ZH, Irwin ST. Malignant obstruction of the left colon. Br J Surg 1994; 81: 1270-6.

3. Tekkis PP, Kinsman R, Thompson MR, Stamatakis JD. The Association of Coloproctology of Great Britain and Ireland study of large bowel obstruction caused by colorectal cancer. Association of Coloproctology of Great Britain, Ireland. Ann Surg 2004; 240: 76-81.

4. Leitman IM, Sullivan JD, Brams D, DeCosse JJ. Multivariate analysis of morbidity and mortality from the initial surgical management of obstructing carcinoma of the colon. Surg Gynecol Obstet 1992; 174: 513-8.

5. Morris EJ, Taylor EF, Thomas JD, et al. Thirty-day postoperative mortality after colorectal cancer surgery in England. Gut 2011; 60: 806-13.

6. Dohmoto M. New method-endoscopic implantation of rectal stent in palliative treatment of malignant stenosis. Endosc Dig 1991; 3: 1507-12.

7. Tejero E, Mainar A, Fernández L, et al. New procedure for the treatment of colorectal neoplastic obstructions. Dis Colon Rectum 1994; 37: 1158-9.

8. Targownik LE, Spiegel BM, Sack J, et al. Colonic stent vs. emergency surgery for management of acute left-sided malignant colonic obstruction: a decision analysis. Gastrointest Endosc 2004; 60: 865-74.
9. Khot UP, Lang AW, Murali K, Parker MC. Systematic review of the efficacy and safety of colorectal stents. Br J Surg 2002; 89: 1096-102.

10. van Hooft JE, van Halsema EE, Vanbiervliet G, et al. Self-expandable metal stents for obstructing colonic and extracolonic cancer: European Society of Gastrointestinal Endoscopy (ESGE) Clinical Guideline. Endoscopy 2014; 46: 990-1053.

11. Saida Y, Enomoto T, Takabayashi K, et al. Outcome of 141 cases of self-expandable metallic stent placements for malignant and benign colorectal strictures in a single center. Surg Endosc 2011; 25: 1748-52.

12. Samper Wamba JD, Fernández Martínez A, González Pastrana L, et al. Efficacy and complications in the use of self-expanding colonic stents: an analysis of 15 years' experience. Radiologia 2015; 57: 402-11.

13. Takahashi H, Okabayashi K, Tsuruta M, et al. Self-expanding metallic stents versus surgical intervention as palliative therapy for obstructive colorectal cancer: a meta-analysis. World J Surg 2015; 39: 2037-44.

14. Abbott S, Eglinton TW, Ma Y, et al. Predictors of outcome in palliative colonic stent placement for malignant obstruction. $\mathrm{Br}$ J Surg 2014; 101: 121-6.

15. Meisner S, Gonzalez-Huix F, Vandervoort JG, et al. Self-expandable metal stents for relieving malignant colorectal obstruction: short-term safety and efficacy within 30 days of stent procedure in 447 patients. Gastrointest Endosc 2011; 74: 876-84.

16. Zhao XD, Cai BB, Cao RS, et al. Palliative treatment for incurable malignant colorectal obstructions: a meta-analysis. World J Gastroenterol 2013; 19: 5565-74.

17. Miłek T, Ciostek P. Implantation of a new enteral stent in obstructive colorectal cancer using interventional radiology in patients over 70 years of age. Videosurgery Miniinv 2015; 10 : 155-60.

Received: 4.05.2017, accepted: 8.08.2017. 